\title{
Mass Attenuation Coefficients of Binderless and Polylactic Acid Added Oil Palm Trunk Particleboard in the Diagnostic Energy Range
}

\author{
Mohana Baskaran", Rokiah Hashim", Mohd Fahmi Mohd Yusoff *, Sabar Bauk ${ }^{1}$, Othman Sulaiman ${ }^{\#}$, \\ Matoshi Sato ${ }^{2}$, Sudesh Kumar ${ }^{3}$ \\ \# School of Industrial Technology, Universiti Sains Malaysia, 11800, Penang, Malaysia. \\ E-mail:mohna23@gmail.com; hrokiah1@gmail.com; osulaiman@gmail.com \\ * School of Physics, Universiti Sains Malaysia, 11800, Penang, Malaysia. \\ E-mail:mfahmi@usm.com \\ ${ }^{1}$ Physics Section, School of Distance Education, Universiti Sains Malaysia, 11800, Penang, Malaysia.
E-mail: sabar@ usm.com \\ ${ }^{2}$ Graduate School of Agricultural and Life Sciences, The University of Tokyo, 1138657, Tokyo, Japan. \\ E-mail:amsato@mail.ecc.u-tokyo.ac.jp \\ ${ }^{3}$ School of Biological Sciences, Universiti Sains Malaysia, 11800, Penang, Malaysia. \\ E-mail:ksudesh@usm.com
}

\begin{abstract}
Two types of oil palm trunk particleboards namely binderless and polylactic acid (PLA) added board were manufactured with a target density of $1.0 \mathrm{~g} / \mathrm{cm}^{3}$. The mass attenuation coefficients of the binderless and PLA added particleboards were determined by using X-ray fluorescence (XRF) photons emanating from high purity metal plates. The energies of the XRF emitted from those metal plates were in the range of $16.59 \mathrm{keV}-25.26 \mathrm{keV}$. The experimental values of the mass attenuation coefficients of the binderless particleboards and the XCOM calculated values for water are comparable. These results suggest that binderless particleboards have the potential to be a phantom material at diagnostic photon energies.
\end{abstract}

Keywords - Mass attenuations coefficients; oil palm trunk; particleboard; polylactic acid (PLA).

\section{INTRODUCTION}

Malaysia is one of the largest producers and exporters of palm oil in the world. With the growth of palm oil industry apparently, massive amount of residues being generated from oil palm plantations every year. Oil palm trunk is considered one of sustainable lignocellulosic material obtained from oil palm plantation. Yet, mostly are left in ground to rot by itself after the replanting process that place every 25 years.

Instead of that, many researchers [1-4] successfully discovered its potential use as raw material in the development of binderless particleboard production. It has attracted keen interest due to its concept that involves process of converting lignocellulosic material into boards by heat treatment without addition of any adhesives [5]. To enhance the basic properties of oil palm particleboard, polylactic acid (PLA) a type of biodegradable polymer which was synthesized from sugar feeds and corn [6], was fabricated in such type of board.

Binderless particleboard offer a significant effect towards ecological problem, thus in this study the mass attenuation coefficient of such type of board was determined to be used as phantom material. The term phantom refers to a stimulated system of tissue equivalent material to evaluate the attenuation coefficients of human body [7].

Generally, the phantom materials are designed to be water equivalent as the basic dose distribution are measured in water phantom where it able to approximate closes radiation absorption and scattering properties of muscle and other soft tissue [8]. In this study, oil palm trunk particleboards are fabricated to density of $1.0 \mathrm{~g} / \mathrm{cm}^{3}$ as to be equivalent to the 
water phantom and its mass attenuation coefficient was measured at photon energy range of $16.59-25.26 \mathrm{keV}$.

\section{MATERIALS AND METHODS}

Oil palm trunks were obtained from an oil palm plantation located in Kedah, Malaysia. They were cut into discs and the bark was removed. The discs were further reduced to small particles and then dried to moisture content ranging from 6 to $8 \%$. In the next step, particles were grounded to fine material with particle size of less than $150 \mu \mathrm{m}$ in length in average. The particles were air-dried until the moisture content reached a constant value of around 7 to $8 \%$.

Polylactic acid (PLA) used in this study were obtained from a fermentation of carbohydrate using $100 \%$ renewable resources like corn as it is starch rich products [9]. The PLA in the form of powder was added at rates of $10 \%$ based on oven dried weight of the particles and manually mixed. Fine particles were manually formed and pre-pressed into homogenous single-layer mat using a forming box of dimension $20.5 \mathrm{~cm} \times 20.5 \mathrm{~cm}$ with target thickness of $0.5 \mathrm{~cm}$ to manufacture particleboards. The mats were then pressed at a temperature of $160{ }^{\circ} \mathrm{C}$ for $20 \mathrm{~min}$ with a pressure of 5 $\mathrm{MPa}$ and a target density of $1.0 \mathrm{~g} / \mathrm{cm} 3$ to form particleboard. Each particleboard was then cut into $5.0 \mathrm{~cm}$ x $5.0 \mathrm{~cm}$ in size to determine the density of samples [10].

TABLE I

THE METAL PLATES AND ITS $\mathrm{K}_{\mathrm{A}}$ ENERGIES (KEV)

\begin{tabular}{|c|c|c|c|c|}
\hline Plate & $\begin{array}{c}\text { Atomic } \\
\text { No. }(\mathbf{Z})\end{array}$ & $\begin{array}{c}\text { Thickness } \\
(\mathbf{m m})\end{array}$ & $\begin{array}{c}\text { Purity } \\
(\boldsymbol{\%})\end{array}$ & $\begin{array}{c}\mathbf{K}_{\boldsymbol{\alpha}} \\
\text { Energy } \\
(\mathbf{k e V})\end{array}$ \\
\hline Niobium (Nb) & 41 & 0.14 & 99.8 & 16.59 \\
\hline Molybdenum (Mo) & 42 & 0.11 & 99.9 & 17.46 \\
\hline Palladium (Pd) & 46 & 0.10 & 99.9 & 21.21 \\
\hline Tin (Sn) & 50 & 0.28 & 99.999 & 25.26 \\
\hline
\end{tabular}

The XRF were used to measure the attenuation coefficients of particleboards by measuring the transmission of X-ray fluorescent photons. A $59.5 \mathrm{keV}$ of $100 \mathrm{mCi}$ Am241 were used to irradiate high purity plates to produce the X-ray fluorescent photons. Niobium ( $\mathrm{Nb}$ ), molybdenum (Mo), palladium (Pd) and tin (Sn) metal plates were used that produced $\mathrm{K}_{\alpha}$ fluorescent X-rays of 16.59 , 17.46, 21.21 and $25.26 \mathrm{keV}$ respectively. The metal plates used and their $\mathrm{K}_{\alpha}$ energies were summarized in Table 1 . The photons emitted were measured using Low-Energy Germanium detector (LEGe). The signals were collected into spectroscopy amplifier and determined from multichannel analyzer (MCA) corresponding to the peak energy. As photon passing through the sample with thickness, $x$, the value of net area was obtained. The net area at region of interest at that spectrum was recorded as $I_{0}$. The graph $-\ln$ $\left(\mathrm{I} / \mathrm{I}_{0}\right)$ versus thickness of particleboard was plotted. The gradient of the line was referred to the linear attenuation coefficient, $\mu$. Its intensity will be attenuated and reduced according to Beer-Lambert's law and calculated as following

$$
I=I_{o} e^{-\mu x}
$$

where $I_{o}$ is the initial intensity of photon, and $\mu$ is the linear attenuation coefficient of sample in $\mathrm{cm}^{-1}$.
The procedures were repeated for PLA added particleboards. Then the metal plate was changed to other metal plates and the same procedure was repeated for each metal plate. Lastly, the mass attenuation coefficients PLA added of oil palm trunk particleboards were obtained by dividing the linear attenuation coefficient to the density of the particleboard. Then its value versus energy was plotted and compared with the mass attenuation coefficient of water calculated using XCOM computer program [11-13].

\section{RESULTS AND DISCUSSION}

It is essential to determine the density of board samples as their compared to that of water $\left(1.0 \mathrm{~g} / \mathrm{cm}^{3}\right)$. The density of each samples as shown in Table 2, were calculated by measurement of lengths, widths and thicknesses, simply by dividing mass over the volume.

TABLE 2

AVERAGE DENSITY OF BINDERLESS (C) AND PLA ADDED (P) OIL PALM TRUNK PARTICLEBOARD

\begin{tabular}{|c|c|c|c|c|}
\hline \multirow{2}{*}{ Sample } & \multicolumn{2}{|c|}{ Measured density $\left(\mathbf{g} / \mathbf{c m}^{3}\right)$} & \multirow{2}{*}{ Standard deviation } \\
\cline { 2 - 4 } & Average & Max. & Min. & \\
\hline $\mathrm{C}$ & 0.9987 & 1.004 & 0.991 & 0.0080 \\
\hline $\mathrm{P}$ & 1.0076 & 1.013 & 0.996 & 0.0083 \\
\hline
\end{tabular}

The measured attenuation coefficient of binderless and PLA added oil palm trunk particleboard were illustrated in Table 3 for different X-ray fluorescent beam energies form niobium $(\mathrm{Nb})$, molybdenum (Mo), palladium $(\mathrm{Pd})$ and tin (Sn) for characteristic X-ray of the target at $\mathrm{K}_{\alpha}$ peak.

TABLE 3

THE LINEAR AND MASS ATTENUATION COEFFICIENT OF BINDERLESS (C) AND PLA ADDED (P) OIL PALM TRUNK PARTICLEBOARD

\begin{tabular}{|c|c|c|c|c|c|c|c|c|}
\hline \multirow{3}{*}{ Sample } & \multicolumn{2}{|c|}{ Nb } & \multicolumn{2}{c|}{ Mo } & \multicolumn{2}{c|}{ Pd } & \multicolumn{2}{c|}{ Sn } \\
& $\mathbf{1 6 . 5 9} \mathbf{~ k e V}$ & \multicolumn{17}{c|}{$\mathbf{1 7 . 4 6} \mathbf{~ k e V}$} & \multicolumn{2}{|c|}{$\mathbf{2 1 . 2 1} \mathbf{~ k e V}$} & \multicolumn{2}{|c|}{$\mathbf{2 5 . 2 6} \mathbf{~ k e V}$} \\
\cline { 2 - 9 } & $\boldsymbol{\mu}$ & $\boldsymbol{\mu} / \boldsymbol{\rho}$ & $\boldsymbol{\mu}$ & $\boldsymbol{\mu} / \boldsymbol{\rho}$ & $\boldsymbol{\mu}$ & $\boldsymbol{\mu} / \boldsymbol{\rho}$ & $\boldsymbol{\mu}$ & $\boldsymbol{\mu} / \boldsymbol{\rho}$ \\
\hline $\mathrm{C}$ & 1.261 & 1.263 & 1.107 & 1.108 & 0.783 & 0.784 & 0.535 & 0.536 \\
\hline $\mathrm{P}$ & 1.341 & 1.304 & 1.245 & 1.235 & 0.818 & 0.812 & 0.582 & 0.578 \\
\hline
\end{tabular}

The comparison between oil palm trunk particleboard with calculated mass attenuation coefficient of water calculated using photon energy database (XCOM) as can be seen in Fig. 1. It was found that the mass attenuation coefficients of binderless and PLA added oil palm trunk particleboard were close to the calculated value for water.

The measurement of goodness of fit was used to determine the discrepancy of particleboard to the calculated value of water. The $\chi^{2}$ test was conducted to measure the closeness of samples to the theoretical prediction value. The value of $\chi 2$ test can be calculated by the following equation:

$$
\chi^{2}=\Sigma\left[\left(\mathrm{y}_{\mathrm{i}}-\mathrm{x}_{\mathrm{i}}\right)^{2} / \sigma(\mu / \rho)^{2}\right]
$$

where $\chi^{2}=$ Chi-squre test value, $\mathrm{y}_{\mathrm{i}}=$ observed values, $\mathrm{x}_{\mathrm{i}}=$ theoretical prediction values and $\sigma=$ error of measurements 


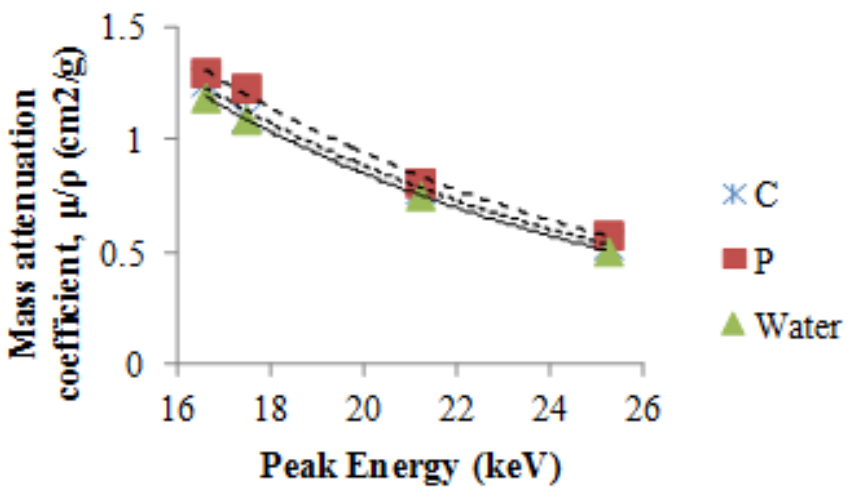

Fig. 1 Mass attenuation coefficient at different $\mathrm{K} \alpha$ energies for binderless (C) and PLA added (P) oil palm trunk particleboard samples compared with calculated XCOM for water

The result of $\chi^{2}$ test on the experimental data for binderless and PLA added oil palm trunk particleboard and the XCOM calculated value for water are given in Table 4. It is clear evident that both the oil palm trunk particleboards were close to the XCOM calculated water with 1.23 for binderless board and 3.55 for PLA added board.

TABLE 4

THE X2 TEST OF MASS ATTENUATION COEFFICIENT OF BINDERLESS AND PLA ADDED OIL PALM TRUNK PARTICLEBOARDS SAMPLES TO XCOM CALCULATED WATER

\begin{tabular}{|c|c|c|}
\hline Energy (keV) & Binderless board & PLA added board \\
\hline 16.59 & 0.15 & 0.14 \\
\hline 17.46 & 0.01 & 0.79 \\
\hline 21.21 & 0.85 & 0.44 \\
\hline 25.26 & 0.22 & 2.18 \\
\hline$\chi^{2}$ & 1.23 & 3.55 \\
\hline
\end{tabular}

\section{CONCLUSIONS}

The mass attenuation coefficient of binderless and PLA added oil palm trunk particleboards were observed as nearest to the calculated XCOM value from water in the $16.59-$ $25.26 \mathrm{keV}$ photon energies range. It is considered that oil palm trunk particleboard as a significant and reliable material for phantom application at diagnostic energy range.

\section{ACKNOWLEDGMENT}

We would like to express their gratitude to The Ministry of Higher Education Malaysia for MyBrain 15 scholarship of Mohana Baskaran. Assistance in raw material supplies by Kuala Lumpur Kepong, Bhd. Northern Branch is appreciated.

\section{REFERENCES}

[1] M. Baskaran, R. Hashim, N. Said, S. M. Raffi, K. Balakrishnan, K. Sudesh, O. Sulaiman, T. Arai, A. Kosugi, Y. Mori, T. Sugimoto, M. Sato, "Properties of binderless particleboard from oil palm trunk with addition of polyhydroxyalkanoates," Composites: Part B, vol. 43, pp. 1109-1116, 2012.

[2] R. Hashim, N. Said, J. Lamaming, M. Baskaran, O. Sulaiman and M. Sato, "Influence of press temperature on the properties of binderless particleboard made from oil palm trunk," Material \& Design, vol. 32, pp. 2520-2555, 2011.

[3] R. Hashim, W. N. A. Wan Nadhari, O. Sulaiman, F. Kawamura, S. Hiziroglu and M. Sato, "Characterization of raw materials and manufactured binderless particleboard from oil palm biomass," Material \& Design, vol. 32, pp. 246-254, 2011.

[4] R. Hashim, N. Saari, O. Sulaiman, F. Kawamura and S. Hiziroglu, "Effect of particle geometry on the properties of binderless particleboard manufactured from oil palm trunk," Material \& Design, vol. 31,pp. 4251-4257, 2010.

[5] K. C. Shen, "Process for manufacturing composite products from lignocellulosic materials," United States Patent 4627951, 1986.

[6] M. U. Wahit, N. I. Akos and W. A. Laftah, "Influence of natural fibers on the mechanical properties and biodegradable of poly(lactic acid) and poly( $\varepsilon$-caprolactone) composites: A review," Polymer Composites, vol. 33(7), pp. 1045-1053, 2012.

[7] F. H. Attix, Introduction to Radiological Physics and Radiation Dosimetrty, New York: John Wiley and Sons, Inc., 1986.

[8] K. Tuffour-Achampong, B. J. B. Nyarko, E. H. K. Akaho, M. Asamoah, R. M. B. Sogbadji and R. G. Abrefah, "Redesign of 241 Am-Be neutron source irradiator facility at NNRI using MCNP-5 code," Annals of Nuclear Energy, vol. 40(1), pp. 60-64, 2012.

[9] M. Ajioka, K. Enomoto, K. Suzuki and A. Yamaguchi, "The basic of poly(lactic acid) produced by the direct condensation polymerization of lactic acid," Journal of Environmental Polymer Degradation, vol. 3(4), pp. 225-234, 1995.

[10] JIS A 5908: 2003, "Particleboards," Japanese Standard Association, Tokyo, Japan, 2003.

[11] M. W. Marashdeh, S. Bauk, A. A. Tajuddin and R. Hashim, "Measurement of mass attenuation coefficients of Rhizophora spp. binderless particleboards in the $16.59-25.26 \mathrm{keV}$ photon energy range and their density profile using x-ray computed tomography," Applied Radiation and Isotopes, vol. 70(4), pp. 656-662, 2012.

[12] C. Constantinous, "Phantom materials for radiation dosimetry. I. Liquids and gels," British Journal of Radiology, vol. 55, pp. 217-224, 1982.

[13] M. J. Berger, and J. H. Hubbell, XCOM: Photon cross-sections on a pns on a personal computer, National Bureau of Standards Information Report. 87-3597. Washington, 1987. 